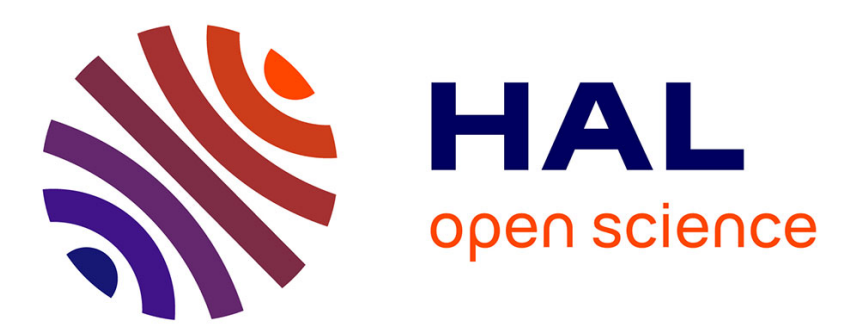

\title{
Equivalent transformation strain and its relation with martensite volume fraction for isotropic and anisotropic shape memory alloys.
}

Karine Lavernhe Taillard, Shabnam Arbab-Chirani, Sylvain Calloch, C. Lexcellent

\section{To cite this version:}

Karine Lavernhe Taillard, Shabnam Arbab-Chirani, Sylvain Calloch, C. Lexcellent. Equivalent transformation strain and its relation with martensite volume fraction for isotropic and anisotropic shape memory alloys.. Mechanics of Materials, 2008, 40 (4-5), pp.151-170. 10.1016/j.mechmat.2007.07.005 . hal-01021389

\section{HAL Id: hal-01021389 \\ https://hal.science/hal-01021389}

Submitted on 9 Jul 2014

HAL is a multi-disciplinary open access archive for the deposit and dissemination of scientific research documents, whether they are published or not. The documents may come from teaching and research institutions in France or abroad, or from public or private research centers.
L'archive ouverte pluridisciplinaire HAL, est destinée au dépôt et à la diffusion de documents scientifiques de niveau recherche, publiés ou non, émanant des établissements d'enseignement et de recherche français ou étrangers, des laboratoires publics ou privés. 
Submitted to "MECHANICS OF MATERIALS", June 2006

Revised, April 2007

EQUIVALENT TRANSFORMATION STRAIN AND ITS

RELATION WITH MARTENSITE VOLUME FRACTION FOR

ISOTROPIC AND ANISOTROPIC SHAPE MEMORY ALLOYS

K. TAILLARD ${ }^{*}$, S. ARBAB CHIRANI** S. CALLOCH ${ }^{* * *}, 1$ and C. LEXCELLENT ${ }^{* * * *}$

*LMT-Cachan, ENS de Cachan/CNRS-UMR 8535/Université Paris 6

61 avenue du Président Wilson, F-94235 Cachan Cedex, FRANCE

** Pôle de Mécanique Brestois, Laboratoire de Recherche en Mécatronique, ENIB

Technopôle Brest-Iroise, F-29280 Plouzané, FRANCE

*** Pôle de Mécanique Brestois, Laboratoire de Mécanique des Structures Navales, ENSIETA

2 rue François Verny, F-29806 Brest Cedex 9, FRANCE

${ }^{* * * *}$ FEMTO-ST, Département de Mécanique, UMR-CNRS 6174

24 chemin de l'Epitaphe, F-25000 Besançon, FRANCE

${ }^{1}$ Corresponding author: Fax: +33 2983487 30, E-mail: sylvain.calloch@ensieta.fr 


\title{
EQUIVALENT TRANSFORMATION STRAIN AND ITS RELATION WITH MARTENSITE VOLUME FRACTION FOR ISOTROPIC AND ANISOTROPIC SHAPE MEMORY ALLOYS
}

by

\author{
K. TAILLARD, S. ARBAB CHIRANI, S. CALLOCH and C. LEXCELLENT
}

\begin{abstract}
The present paper deals with the superelastic behavior of both isotropic and anisotropic Shape Memory Alloys (SMA). Recently, a macroscopic model, which permits to simulate the superelasticity of SMA under complex multi-axial loading, has been proposed by Bouvet et al. (2004). In this model, a conjecture concerning the proportionality of the equivalent transformation strain with the martensite volume fraction has been adopted. The main goal of this study is to show the validity of this conjecture when the stress state is multi-axial. In a first part, the case of isotropic SMA is considered. An equivalent stress and an equivalent transformation strain are introduced. In the second section, the case of anisotropic SMA is considered. The previous equivalent stress and equivalent transformation strain are generalized to take into account the anisotropy of the material. The relation between the equivalent transformation strain and the martensite volume fraction is discussed by using, on one hand, experimental results under proportional tension-torsion loadings and, on the other hand, a polycrystalline model.
\end{abstract}

Keywords: Superelasticity; Equivalent stress; Equivalent transformation strain; Resistivity; Experimental investigation; Polycrystalline model; Macroscopic model; Multi-axial loadings 


\section{Introduction}

The Shape Memory Alloys (SMA) specific behavior is due to a solid-solid phase transformation called martensitic transformation: according to the steels, the high temperature phase and the low temperature phase are called austenite and martensite, respectively. The transformation consists mainly in a shear, without volume change, which can be activated either by stress or temperature. Among the various mechanical properties of SMA, in this work, the superelastic behavior is considered. In this case the martensitic transformation is only stress induced whereas the temperature remains constant and greater than the $A_{f}$ temperature. The two main characteristics of the SMA superelastic behavior are, on the one hand, a typical hysteretic behavior and, on the other hand, the absence of residual strain after a total strain of $6 \%$ to $8 \%$ (for a polycrystalline NiTi SMA): the transformation strain is totally recoverable.

Superelasticity of SMA has received considerable attention over the last twenty years. Several types of superelasticity tests under uni-axial and multi-axial loading have been developed to understand and model the mechanisms of formation and disappearance of martensite variants. Today, it can be concluded that exhaustive experimental investigations under uni-axial conditions on the superelasticity behavior of SMA are reported in the literature. Many effects have been studied under uni-axial loadings and over a large temperature range. Particularly, the effects of temperature (Wayman, 1983; Berveiller and Fischer, 1997), strain rate (Lim and McDowell, 1999; Balandraud et al., 2000) and loading direction (tension or compression) (Patoor et al., 1995; Gall et al., 1997; Liu et al., 1998) have been investigated. Moreover, the influence of uni-axial stress on martensite plates substructures has been studied (Tan and $\mathrm{Xu}$, 1990; Marketz and Fischer, 1996). Futhermore, for last years, some experimental investigations under multi-axial loadings have been performed. For instance, the tensiontorsion tests on Cu-Al-Zn-Mn of Sittner et al. (1995), on Cu-Zn-Al of Rogueda et al. (1996), on Ni-Ti of Lim and McDowell (1999), Raniecki et al. (2001), Helm and Haupt (2001 \& 2003), the triaxial proportional tests of Gall et al. (1998), the biaxial tension tests of Vivet and Lexcellent (1999) and the recent biaxial compression tests on Cu-Al-Be of Bouvet et al. (2002 $\&$ 2004). These recent experimental results show clearly that the superelastic behavior of SMA is influenced by the multi-axial stress state.

In parallel, constitutive laws for superelasticity have been developed following three different approaches depending on the chosen scale level (micro level, micro-macro level and macro level). The micro-level models are based on the description of effects occurring at the microscale level, such as nucleation, interface motion, twin growth, etc... They do not consider 
phase volume fractions as a priori internal variables, but as a consequence of interfaces movements. The interested readers can find more details in the following references (Falk, 1980, 1983, 1987, 1989; Ball and James, 1987, 1992...). The micro-macro-level models, originated by Patoor et al. (1988) study combine micro-mechanical ingredients (such as habit planes, martensite variants, etc...) and thermodynamics tools. The constitutive equations are defined on a micro-scale and a localization process is therefore needed to determine the local stress state. Moreover, the macro quantities are obtained from the micro quantities through the use of proper homogenization techniques (Patoor et al., 1994; Fischer and Tanaka, 1992; Fischer et al., 1994; Lexcellent et al., 1996; Boyd and Lagoudas, 1996; Tokuda et al., 1999; Huang and Zhu, 2002, ). The macro-level models deal with macroscopic quantities, which lead, only, to a description of the global thermomechanical behavior (Tanaka, 1986; Raniecki et al., 1992; Raniecki and Lexcellent, 1994; Atanackovic and Müller, 1995; Fremond, 1987, 1990; Chrysochoos et al., 1993, 1995; Boyd and Lagoudas, 1994; Raniecki and Lexcellent, 1998; Bouvet et al. 2004; Lexcellent and Blanc, 2004; Lexcellent et al. 2006...).

The advantages and disadvantages of the different approaches can be summarized by the following general remarks. First, the models obtained by the macroscopic approaches are generally easy to use and enable quick computations but, on the other hand, are often limited from a predictive point of view. Concerning the micro-macro approaches, it is much more predictive but a large number of internal variables is introduced. That is the reason for which micromechanical models are computationally time-intensive and still remain difficult to be used in structural engineering applications. The micro-level approach is more suitable for the fundamental development work with real physical description of phenomena than the quantitative macroscopic behavior description (Patoor et al., 2006; Lagoudas et al., 2006).

Recently, a macroscopic model, which permits to simulate the SMA superelasticity under complex multi-axial loadings, has been proposed (Bouvet et al., 2004). The originality of this model is that, the elastic domain of the material, in its two-phased state, is given by the intersection of two transformation surfaces. The first one permits to control the forward transformation (i.e., austenite-to-martensite), and the second one the reverse transformation (i.e., martensite-to-austenite). The reorientation mechanism, which is produced only under non-proportional multi-axial loading, is activated when the loading point is situated at the intersection of these two transformation surfaces. None supplementary variable is introduced in the model, the reorientation is modelized correctly (at the adopted description level) by simultaneous forward and reverse transformations. This model has been validated by considering a large base of multi-axial testing under proportional and non-proportional 
loadings. Always in this model, a conjecture, already used by other authors (Juhasz et al., 2002; Helm and Haupt, 2003), has been adopted concerning the proportionality between the equivalent transformation strain and the martensite volume fraction. Up to now, this conjecture has been only validated by experimental observations under uni-axial tension loading (Vacher and Lexcellent, 1991).

So, the main goal of this work is to propose some investigations to show the validity of the relation between martensite volume fraction and the equivalent transformation strain when the stress state is multi-axial. The validation will be discussed, on the one hand, by considering a series of experimental results under tension-compression-torsion loadings on a $\mathrm{Cu}-\mathrm{Al}-\mathrm{Be}$ SMA and, on the other hand, by using a polycrystalline model (Patoor and Berveiller, 1997). As this micromechanical model correctly describes the superelastic behavior of SMA, it is used like a "virtual testing machine" to supply a pseudo-experimental database. By turns, isotropic and anisotropic SMA cases are considered.

The present paper consists of two main sections. In the first one, the isotropic SMA case is considered. Equivalent stress and transformation strain are introduced. Then, the proportionality between the equivalent transformation strain and the martensite volume fraction is discussed. In the second section, the anisotropic SMA case is considered. The previous equivalent stress and equivalent transformation strain are generalized to take into account the anisotropy of the material. The relation between the equivalent transformation strain and the martensite volume fraction is discussed by using, on one hand, the experimental results under proportional tension-compression-torsion loadings and, on the other hand, numerical results obtained with the polycrystalline model on a textured.

\section{Relation between martensite volume fraction and transformation strain: isotropic} SMA case

In the model proposed by Bouvet et al. (2004), a conjecture has been adopted concerning the proportionality between the equivalent transformation strain and the martensite volume fraction. Up to now, this conjecture has been validated only in the case of uni-axial tension loading (Vacher and Lexcellent, 1991). Our purpose here, is to show the validity of this conjecture when the stress state is multi-axial. As our SMA is not isotropic, the polycrystalline model from Patoor and Berveiller (1997) is used as a virtual testing machine. In the first step, this polycrystalline model is described in detail. In the second step, the definitions of equivalent stress and equivalent transformation strain in the case of isotropic SMA are proposed. Finally, it is shown, by simulating 24 proportional loading paths, that 
there is a linear relation between martensite volume fraction and equivalent transformation strain.

\subsection{Constitutive equations of the polycrystalline model}

The polycrystalline model used in this study has been developed by Patoor and Berveiller (1997). It is based on the self consistent approach. The representative elementary volume is defined by a polycrystal (i.e., a set of crystal orientations). Loading is evaluated at grain scale using the localization tensor. Considering the local loading state, the martensite activable variants are detected and the volume fraction of each variant and the induced transformation strain are calculated. This operation is realized for all the grains (i.e., crystal orientations) of the polycrystal. By this way, the microstructure evolution (i.e., the evolution of the martensite volume fraction of each variant in each grain) can be followed during loading. The martensite volume fraction can be calculated at different scale. The grain orientations of the polycrystal permit to define the crystallographic texture of the material so the isotropy or anisotropy of the SMA produced during the forming process can be taken into account.

\subsubsection{Localization}

The one site self consistent approach using the Kröner inclusion is used to obtain the localization tensor.

$$
\xi_{i j}=A_{i j k l} \dot{E}_{k l}
$$

where $\dot{\varepsilon}_{i j}$ is the increment of the local total strain tensor, $\dot{E}_{k l}$ is the increment of macroscopic total strain tensor and $A_{i j k l}$ is the localization tensor given by:

$$
A_{i j k l}=\left[I_{i j k l}-\Gamma_{i j m n}^{e f f}\left[l_{i j k l}-L_{i j k l}^{e f f}\right]\right]^{l}
$$

where $I_{i j k l}$ is the identity tensor, $\Gamma_{i j m n}^{e f f}$ is the effective Green tensor, $l_{i j k l}$ is the local tangent modulus and $L_{i j k l}^{\text {eff }}$ is the effective tangent modulus.

\subsubsection{Local evolution laws}

The transformation criterion is the following:

$$
\varepsilon_{p q}^{n} \sigma_{p q}=B\left(T-M_{s}\right)+\sum_{m} H^{n m} f^{m}
$$

where $\varepsilon_{p q}^{n}$ is the transformation strain tensor of variant " $n$ " defined by Eq. (2.4). B is a material parameter which permits to define the chemical potential. $\mathrm{T}$ is the temperature of the aggregate considered as uniform. $\mathrm{M}_{\mathrm{s}}$ is the martensite start temperature. $H^{n m}$ is the 
interaction matrix describing weak or strong interaction between the formed martensite variants (Niclaeys et al. 2002) and $f^{m}$ is the volume fraction variant " $m$ ".

$$
\varepsilon_{p q}^{n}=g \cdot R_{p q}^{n}
$$

where $\mathrm{g}$, the transformation strain amplitude, is a material parameter and $R_{p q}^{n}$ is the orientation tensor of variant " $n$ ".

The internal variables are the volume fraction of each variant. Their evolutions are obtained by the derivation of thermodynamical potential (Entemeyer, 1996).

$$
\dot{\Im}^{n}=\sum_{m}\left({ }^{*} H^{n m}\right)^{-1} \varepsilon_{p q}^{n} C_{p q r s} \hat{\varepsilon}_{r s}
$$

with

$$
{ }^{*} H^{n m}=H^{n m}+\varepsilon_{p q}^{n} C_{p q r s} \varepsilon_{r s}^{m}
$$

where $C_{p q r s}$ is the rigidity tensor and $\dot{\varepsilon}_{r s}$ is the increment of the total strain tensor at grain level.

The local tangent modulus expression is given by:

$$
l_{i j k l}=C_{i j k l}-C_{i j r s} \sum_{n, m} \varepsilon_{r s}^{n}\left(H^{n m}\right)^{-1} \varepsilon_{p q}^{n} C_{p q k l}
$$

\subsubsection{Homogenization}

The effective tangent modulus is calculated using the localization tensor and the local tangent modulus.

$$
L_{i j k l}^{e f f}=\sum_{N} l_{i j k l}^{N} A_{i j k l}^{N} F^{N}
$$

$N$ is the grain number and $F^{N}$ is the volume fraction of grain number " $\mathrm{N}$ ".

The macroscopic behavior is given by:

$$
\dot{E}_{i j}=L_{i j k l}^{e f f} \dot{E}_{k l}
$$

$\dot{\Sigma}_{i j}$ is the increment of macroscopic stress tensor.

\subsubsection{Data of the model}

24 martensite variants forming 6 self-accommodating groups of a CuAlBe SMA are considered. They are characterized by the normal to the habit plane and the transformation direction. They are [ $\left[\begin{array}{lll}1 & 1 & 4\end{array}\right]$ type. The transformation strain amplitude, g, is the same for all the variants and it is about 0.23 . The parameters of the interaction matrix are $50 \mathrm{MPa}$ describing the weak interaction and $260 \mathrm{MPa}$ for the strong one (Siredey et al., 1999). The parameter B 
defined in Eq. (2.3) is about $0.23 \mathrm{MPa} \cdot \mathrm{K}^{-1}$. The elasticity is supposed to be isotropic and the same for the two phases.

The polycrystalline material is represented by 1000 grains with different orientations. An isotropic and a drawn texture have been used to describe an isotropic and an anisotropic SMA. To obtain the drawn texture, an elasto-plastic model describing the behavior of polycrystalline metals, based on the self-consistent scale transition method (Lipinski, 1992) has been used. A drawn loading has been applied to an isotropic texture of FCC metals until 50\% of equivalent von Misès strain. So, a transverse isotropic behavior is obtained.

\subsection{Macroscopic approach}

\subsubsection{Equivalent stress for isotropic SMA}

For isotropic SMA the equivalent stress depends on the three independent stress tensor invariants:

$$
\left\{\begin{array}{l}
P=\operatorname{tr}(\underline{\sigma}) \\
\bar{\sigma}=\sqrt{\frac{3}{2} \operatorname{dev}(\underline{\sigma}): \operatorname{dev}(\underline{\sigma})} \text { with } \operatorname{dev}(\underline{\sigma})=\underline{\sigma}-\frac{1}{3} \operatorname{tr}(\underline{\sigma}) \underline{I} \\
y_{\sigma}=\frac{27}{2} \frac{\operatorname{det}(\operatorname{dev}(\underline{\sigma}))}{\bar{\sigma}^{3}}
\end{array}\right.
$$

As the martensitic transformation is volume invariant, the equivalent stress is independent of the first stress invariant. To describe the well-known tension-compression asymmetry (Gall et al., 1997, Liu et al., 1998, Patoor et al., 1995), Bouvet et al. (2002, 2004) proposed the following equivalent stress:

$$
\sigma_{e q}=\sigma_{e q}\left(\bar{\sigma}, y_{\sigma}\right)=\bar{\sigma} \cdot g\left(y_{\sigma}\right)
$$

with

$$
g\left(y_{\sigma}\right)=\cos \left(\frac{\cos ^{-1}\left(1-a\left(1-y_{\sigma}\right)\right)}{3}\right)
$$

Where $a$ is a material parameter permitting to fit the tension-compression asymmetry.

This definition of equivalent stress yields to a convex criterion (Bigoni and Piccolroaz, 2004) for all values of $a$ varying from 0 to 1 : when $a$ equals to 0 the criterion is the same as the von Misès criterion and when $a$ equals to 1 , the criterion presents its maximal tensioncompression asymmetry. 
The value of the material parameter $a$ is determined using only the "yield" stresses in pure tension, $\sigma_{t}$, and in pure compression, $\sigma_{c}$, as the solution of:

$$
a=\frac{1}{2}\left[1-\cos \left\{3 \cos ^{-1}\left(\frac{\sigma_{t}}{\sigma_{c}}\right)\right\}\right]
$$

\subsubsection{Initial "yield" surface for isotropic SMA}

The initial "yield" surface, $f=0$, linked to the equivalent stress (Eq. (2.11)), is defined by the following equation:

$$
f=\sigma_{e q}-\sigma_{t}=0
$$

Insofar as our $\mathrm{Cu}-\mathrm{Al}-\mathrm{Be} \mathrm{SMA}$ is not isotropic (see section 3.2.4.), the polycrystalline model has been used as a "virtual testing machine" to validate the definition of the initial "yield" surface (Eq. (2.14)). Twelve simulations have been performed in the two planes $\left(\sigma_{11}, \sigma_{22}\right)$ and $\left(\sigma_{11}, \sigma_{12}\right)$ on an isotropic crystallographic texture of 1000 grains. Figures 1 and 2 shows the twenty-four proportional loadings considered.

Figures 3 and 4 show the "yield" surfaces obtained, on the one hand, with the polycrystalline model and, on the other hand, with the macroscopic approach $\left(\sigma_{t}=150 \mathrm{MPa}\right.$ and $\left.a=0.7\right)$. The agreement between these two sets of data is excellent. As only two points were used to identify the two coefficients $\sigma_{t}$ and $a$, these results validate the relevance of the equivalent stress, $\sigma_{e q}$, proposed for isotropic SMA.

\subsubsection{Equivalent transformation strain}

To ensure the coherence of the equivalent transformation strain with the equivalent stress (Eq.(2.11)), the equality between the phase transformation power under proportional loading, $P^{t r}=\underline{\sigma}: \underline{\dot{\varepsilon}}^{t r}$, and the equivalent transformation power $P_{e q}^{t r}=\sigma_{e q} \cdot \dot{\varepsilon}_{e q}^{t r}$ (Bouvet et al., 2004) should be verified (White and Drucker, 1950; Hill, 1979, 1987):

$$
\sigma_{e q} \dot{\xi}_{e q}^{t r}=\underline{\sigma}: \underline{\underline{\varepsilon}}^{t r}
$$

This relation implies that the response of an isotropic SMA for all multi-axial proportional loading have the same representation on the $\left(\varepsilon_{e q}^{t r}, \sigma_{e q}\right)$ plane.

The normality rule is also assumed. It means that the direction of transformation strain rate is supposed to be normal to the "yield" stress surface, $f$ : 


$$
\underline{\dot{\varepsilon}}^{t r}=\dot{\lambda} \frac{\partial f}{\partial \underline{\sigma}}=\dot{\lambda} \frac{\partial \sigma_{e q}}{\partial \underline{\sigma}}=\dot{\lambda} \underline{K}_{\sigma}
$$

where $\dot{\lambda}$ is the superelastic multiplier and $\underline{K}_{\sigma}$ is the normal to the "yield" surface at the loading point.

For isotropic SMA, the following result can be obtained (Raniecki and Lexcellent, 1998; Bouvet et al., 2004):

$$
\underline{K}_{\sigma}=\frac{\partial \sigma_{e q}}{\partial \underline{\sigma}}=\frac{3}{2} g\left(y_{\sigma}\right) \cdot \underline{N}_{\sigma}+\frac{9}{2} g^{\prime}\left(y_{\sigma}\right) \cdot\left(3 \cdot \underline{N}_{\sigma}^{2}-y_{\sigma} \cdot \underline{N}_{\sigma}-\frac{2}{3} \cdot \underline{I}\right)
$$

where $I$ is the unit tensor and

$$
\begin{aligned}
& \underline{N}_{\sigma}=\frac{\operatorname{dev}(\underline{\sigma})}{\bar{\sigma}} \\
& g^{\prime}\left(y_{\sigma}\right)=\frac{d g\left(y_{\sigma}\right)}{d y_{\sigma}}
\end{aligned}
$$

and $g\left(y_{\sigma}\right)$ is given by the equation (2.12).

Therefore:

$$
\underline{\sigma}: \underline{\dot{\varepsilon}}^{t r}=\dot{\lambda} \cdot \underline{\sigma}: \underline{K}_{\sigma}=\dot{\lambda} \cdot \sigma_{e q} \Rightarrow \dot{\varepsilon}_{e q}^{t r}=\dot{\lambda}
$$

Using equation (2.20), the superelastic multiplier can be calculated:

$$
\dot{\boldsymbol{q}}=\dot{\boldsymbol{\varepsilon}}_{e q}^{t r}=\sqrt{\frac{\underline{\boldsymbol{\varepsilon}}^{t r}: \underline{\underline{\varepsilon}}^{t r}}{\underline{K}_{\sigma}: \underline{K}_{\sigma}}}=\frac{\overline{\dot{\boldsymbol{\varepsilon}}^{t r}}}{\sqrt{g^{2}\left(y_{\sigma}\right)+9 \cdot\left(g^{\prime}\left(y_{\sigma}\right)\right)^{2} \cdot\left(1-y_{\sigma}{ }^{2}\right)}}
$$

$\overline{\dot{\varepsilon}^{t r}}$ is the von Misès equivalent transformation strain rate defined by:

$$
\overline{\dot{\varepsilon}^{t r}}=\sqrt{\frac{2}{3} \underline{\dot{\varepsilon}}^{t r}: \underline{\dot{\varepsilon}}^{t r}}
$$

And the equivalent transformation strain is defined like the equivalent transformation strain rate:

$$
\varepsilon_{e q}^{t r}=\frac{\overline{\varepsilon^{t r}}}{\sqrt{g^{2}\left(y_{\sigma}\right)+9 \cdot\left(g^{\prime}\left(y_{\sigma}\right)\right)^{2} \cdot\left(1-y_{\sigma}^{2}\right)}}
$$

With this definition, the equivalent transformation strain depends on the third stress invariant, $y_{\sigma}$. To avoid that, it is possible to calculate $y_{\sigma}$ as a function of $\underline{\varepsilon}^{t r}$ for every proportional loading path. This function cannot be analytically determined, and an approximation is so used: 


$$
\frac{1}{\sqrt{g^{2}\left(y_{\sigma}\right)+9 \cdot\left(g^{\prime}\left(y_{\sigma}\right)\right)^{2} \cdot\left(1-y_{\sigma}^{2}\right)}} \approx \frac{g\left(-y_{\varepsilon^{t r}}\right)}{g(-1)}
$$

Where $y_{\varepsilon^{\prime \prime}}$ is the third transformation strain tensor invariant, defined by:

$$
y_{\varepsilon^{t r}}=4 \frac{\operatorname{det}\left(\varepsilon^{t r}\right)}{{\overline{\varepsilon^{t r}}}^{3}}
$$

Finally, an equivalent transformation strain coherent with the equivalent stress has been defined:

$$
\varepsilon_{e q}^{t r}=\overline{\varepsilon^{t r}} \frac{g\left(-y_{\varepsilon^{t r}}\right)}{g(-1)}
$$

Figure 5 shows the results given by the polycrystalline simulations in the $\left(\varepsilon_{e q}^{t r}, \sigma_{e q}\right)$ plane for the 24 loading paths. It can be observed that the difference between the 24 curves is very small. This result permits to validate the definition of the equivalent transformation strain for isotropic SMA, $\varepsilon_{e q}^{t r}$.

\subsubsection{Relation between martensite volume fraction and equivalent transformation strain}

The macroscopic model proposed by Bouvet et al. (2004) uses the transformation strain, $\underline{\varepsilon}^{t r}$, as an internal variable, and postulates that the volume fraction of martensite, $z$, is a function of the equivalent transformation strain, $\varepsilon_{e q}^{t r}$ :

$$
z=\frac{\varepsilon_{e q}^{t r}}{\gamma}
$$

Our purpose here is to verify the proportionality relation between these two quantities using micro-macro simulations. Figure 6 shows the evolutions of the martensite volume fraction, $\mathrm{z}$, (i.e., the average of microscopic martensite volume fractions) versus the equivalent transformation strain, $\varepsilon_{e q}^{t r}$ (Eq.(2.25)) for the 24 proportional loading paths (figures 1 and 2). 
Figure 6 shows that, for the 24 loading paths considered, the $24\left(z, \varepsilon_{e q}^{t r}\right)$ curves are identical. It is also shown that, excepted for the beginning of the martensitic transformation, the martensite volume fraction, $\mathrm{z}$, is a linear function of the equivalent transformation strain, $\varepsilon_{e q}^{t r}$. At the beginning, a rupture in the slopes of the curves can be observed. This phenomenon is only due to a numerical cause and is not representative of the real behavior of SMA. It may provide from too well oriented grains that early begin to transform into martensite (Entemeyer, 1996).

\subsubsection{Conclusions}

Using simulations of a micro-macro model (Patoor and Berveiller, 1997), an equivalent stress and an equivalent transformation strain have been defined for isotropic SMA. Moreover, it has been shown that there is a linear relation between martensite volume fraction and equivalent transformation strain in the isotropic SMA case.

\section{Relation between martensite volume fraction and transformation strain: anisotropic}

\section{SMA case}

In this part, the relation between martensite volume fraction and equivalent transformation strain is generalized to the anisotropic SMA case. So, the equivalent stress and the equivalent transformation strain introduced in the previous section have been modified to take into account the anisotropy of our material. The anisotropic equivalent stress, $\sigma_{e q \text { ani }}$, is developed from the isotropic equivalent stress (Eq.(2.11)), using a dilated stress tensor concept, $\underline{\widetilde{\sigma}}$, obtained from $\underline{\sigma}$ by an affine transformation (Sobodka, 1969; Boehler and Sawczuck, 1970; Barlat and Lian, 1989, Barlat et al., 1991; Karafillis and Boyce, 1993). The equivalent transformation strain, linked to $\sigma_{e q \text { ani }}$, has been proposed by considering a generalization of the equivalent transformation power that permits to take into account the anisotropy of the transformation energy.

The analyses of the results are made by using, on one hand, numerical micro-macro simulations and, on the other hand, experimental data under tension-compression-torsion on a $\mathrm{Cu}-\mathrm{Al}-\mathrm{Be} \mathrm{SMA}$.

\subsection{Material: $\mathrm{Cu}-\mathrm{Al}-\mathrm{Be}$ SMA}

All experimental results presented hereafter have been obtained on a polycrystalline $\mathrm{Cu}-\mathrm{Al}-\mathrm{Be}$ SMA composed of $87.75 \mathrm{wt} \%$ copper, $11.33 \mathrm{wt} \%$ aluminum and $0.49 \mathrm{wt} \%$ beryllium. It has 
been provided by the Tréfimétaux Company. The samples have been obtained by drawing, heat treated at $650^{\circ} \mathrm{C}$ during 20 minutes and then quenched in boiling water during 1 hour.

The four transformation temperatures at free stress state have been determined using electrical resistance measurements (austenite start temperature: $\mathrm{A}_{\mathrm{s}}=25^{\circ} \mathrm{C}$, austenite finish temperature: $\mathrm{A}_{\mathrm{f}}=38^{\circ} \mathrm{C}$, martensite start temperature: $\mathrm{M}_{\mathrm{s}}=22^{\circ} \mathrm{C}$, martensite finish temperature: $\mathrm{M}_{\mathrm{f}}=4^{\circ} \mathrm{C}$ ) (figure 7).

\subsection{Experimental “yield” stress surfaces}

In order to obtain a large database of experimental "yield" stress surfaces, three types of mechanical tests have been performed: tension-compression-internal pressure and tensioncompression-torsion on tubular specimen and bi-compression on cubic specimen. In this work, "yield" surface is defined conventionally at a certain off-set of transformation strain (e.g., $0.1 \%$ ). More details concerning the experimental procedure can be found in (Bouvet et al., 2002).

\subsubsection{Tension-compression-internal pressure tests}

The tests have been carried out on a Schenck axial hydraulic testing machine. The axial actuator has a load capacity of $63 \mathrm{kN}$. An 800 bar hydraulic pump has been added to perform internal pressure loading. Axial and hoop strains have been measured using a rosette-type strain gauge glued on the external diameter of the tubular specimen. Figure 8 shows the geometry of the thin walled tubular sample.

A specimen has been subjected to a series of nine proportional loading paths. Figure 9 shows the shape of the experimental transformation "yield" surface in the $\left(\sigma_{11}, \sigma_{22}\right)$ upper halfplane. The well-known tension-compression asymmetry can be observed.

\subsubsection{Tension-compression-torsion tests}

The tests have been carried out on a MTS axial-torsion hydraulic testing machine. The axial and rotary actuators have a load capacity of $100 \mathrm{kN}$ and $1.2 \mathrm{kN} . \mathrm{m}$, respectively. Axial and shear strains were measured using a rosette-type strain gauge glued on the external diameter of the tubular specimen. The samples are the same thin walled tubes as for the tensioncompression-internal pressure tests (figure 8).

Twelve proportional loading paths have been carried out. Figure 10 shows the shape of the transformation "yield" surface in the $\left(\sigma_{11}, \sigma_{12}\right)$ plane. 


\subsubsection{Biaxial compression tests}

The tests were performed on the Schenck multi-axial testing machine, ASTREE. The basic idea of the biaxial compressive test is to load a cube of $\mathrm{Cu}-\mathrm{Al}-\mathrm{Be}$ alloy in compression along two perpendicular directions. The main difficulty of this test consists in applying uniformly the load on each face of the specimen without friction; that is why the load is transferred through 296 rods to each face. Experimental procedures and first experimental results are described in details in Bouvet et al. (2002). Nine proportional loading paths have been carried out. Figure 11 shows the shape of the transformation "yield" surface in the $\left(\sigma_{22}, \sigma_{33}\right)$ quarterplane.

\subsubsection{Comparison between experimental results and the isotropic transformation surface}

Figures 9, 10 and 11 show, in the three planes $\left(\sigma_{11}, \sigma_{22}\right),\left(\sigma_{11}, \sigma_{12}\right)$ and $\left(\sigma_{22}, \sigma_{33}\right)$, the comparison between experimental data and the macroscopic "yield surface" for isotropic SMA $\left(\sigma_{t}=140 \mathrm{MPa}\right.$ and $\left.a=0.65\right)$. Figures 9 and 11 show that the agreement is excellent in the planes $\left(\sigma_{11}, \sigma_{22}\right)$ and $\left(\sigma_{22}, \sigma_{33}\right)$. But, figure 10 shows a strong anisotropy in the plane $\left(\sigma_{11}, \sigma_{12}\right)$. Indeed, the macroscopic criterion gives a value of $90 \mathrm{MPa}$ for the yield stress under pure torsion whereas the experimental value reaches $145 \mathrm{MPa}$. So, more general "yield" surfaces are needed to take into account these observations.

\subsection{Determination of microstructure evolution under tension-compression-torsion loading by} electrical resistance measurements

As the austenite and the martensite phases have different resistivities (e.g., $\rho_{A} \approx 6.210^{-8} \Omega \mathrm{m}$ and $\rho_{M} \approx 8,210^{-8} \Omega m$, respectively), the microstructure evolution (i.e., martensite volume fraction) can be deduced from the sample electrical resistance variations during loading (Vacher and Lexcellent, 1991; Gonzalez, 2002; Kotil et al., 2003). This experimental technique has been performed under tension-compression-torsion proportional loadings on tubular specimen (figure 8 ) at constant temperature $\left(\mathrm{T}=50^{\circ} \mathrm{C}\right)$.

\subsubsection{Relation between the martensite volume fraction and the sample electrical resistance}

During the tests, to determine the martensite volume fraction evolution, the sample electrical resistance has been measured using the 4-wire lead measurement method, which cancels lead resistance errors inherent in 2-wire systems. The sample electrical resistance is given by:

$$
R=\rho \frac{L}{S}
$$


where $\rho$ is the resistivity of the material, $L$ is the specimen length and $S$ is the specimen section.

If the sample volume is assumed as a constant, $V_{0}=S_{0} . L_{0}=S . L$ (i.e., the volume variation, due to the elastic deformation, is neglected), the sample electrical resistance can be written:

$$
R=\rho \frac{L^{2}}{V_{0}}
$$

Figure 12 shows the evolution of the sample electrical resistance versus the total axial strain during a tension-compression test. During a tension-compression-torsion test at constant temperature, the electrical resistance variation is given by:

$$
\begin{aligned}
& \Delta R=\rho \frac{2 L_{0}}{V_{0}} \Delta L+\frac{L_{0}^{2}}{V_{0}} \Delta \rho \\
& \Delta R=\rho \frac{2 L_{0}}{S_{0}} \frac{\Delta L}{L_{0}}+\frac{L_{0}^{2}}{V_{0}} \Delta \rho \\
& \Delta R=\rho \frac{2 L_{0}}{S_{0}} \varepsilon_{11}+\frac{L_{0}^{2}}{V_{0}} \Delta \rho
\end{aligned}
$$

This last equation (Eq. (3.5)) shows that the electrical resistance variation is caused, on one hand, by a resistivity change, $\Delta \rho$, (i.e., linked to martensite transformation), and, on the other hand, by the total axial strain of the sample, $\varepsilon_{11}$. It should be noted that a shear strain has no effect on the electrical resistance variation. The effects of $\Delta \rho$ and $\varepsilon_{11}$ contributions during a tension-compression loading can be observed on figure 12 .

During the first part of the tension test, the behavior is elastic without phase transformation. So, the electrical resistance variation is only due to the axial strain. In the second part, the electrical resistance change is due to both axial strain and phase transformation. Concerning the first part of the compression test (i.e., elastic part), the electrical resistance variation is negative because the axial strain is negative (Eq. (3.5)). In the second part (i.e., after the yield stress), the electrical resistance variation is due to a negative axial strain effect (i.e., $\varepsilon_{11}<0$ ) and a positive martensite transformation effect (i.e., $\Delta \rho>0$ ).

To obtain the resistance variation related only to the martensite transformation, a corrected electrical resistance, $R_{c}$, should be defined by removing the geometry effect from the measured electrical resistance, $R$. The correction to the measured electrical resistance is made as follow:

$$
R_{c}=R-\kappa \varepsilon_{11}
$$


Where $\kappa$ is a coefficient that has been identified to obtain a $\left(R_{c}, \mathcal{E}_{11}\right)$ symmetrical graph (i.e., we assume that the phase transformation has the same effect on electrical resistance variation under tension or under compression) (figure 13).

Figure 13 shows that the corrected electrical resistance, $R_{c}$, is quasi-constant in the elastic deformation zone of the tension-compression test.

So, the martensite volume fraction, $\mathrm{z}$, can be calculated from the corrected electrical resistance, $R_{c}$, by using a mean law (i.e., differential model) (Milton, 2002):

$$
z=1-\frac{R_{c}-R_{M}}{R_{A}-R_{M}}\left(\frac{R_{A}}{R_{c}}\right)^{\frac{2}{3}}
$$

where $R_{M}$ and $R_{A}$ are the sample electrical resistance at martensite and austenite state at $\mathrm{T}=50^{\circ} \mathrm{C}$, respectively. These two values can be determined on figure 7 .

Figure 14 shows the martensite volume fraction versus the axial transformation strain during a loading-unloading tension test. The proportionality between the axial transformation strain, $\mathcal{E}^{t r}$, and the martensite volume fraction, $z$, is observed (figure 14). This result has already been showed by Vacher and Lexcellent in 1991 on a Cu-Al-Zn polycrystalline SMA.

\subsubsection{Evolution of martensite volume fraction under tension-compression-torsion loading}

A series of nine tests under proportional tension-compression-torsion loading has been performed on a tubular specimen. Figure 15 shows the loading paths considered. During the nine tests, the electrical resistance variation has been measured. Figure 16 shows the martensite volume fraction, z, Eq. (3.7), versus the isotropic equivalent transformation strain, $\varepsilon_{e q}^{t r}$, Eq. (2.25).

For each loading path, the proportionality between the isotropic equivalent transformation strain, $\varepsilon_{e q}^{t r}$, and the martensite volume fraction, $z$, is observed (figure 16). Nevertheless, the slopes are quite different and seem to be influenced by the loading direction. But, this first reported results on figure 16 does not take into account the anisotropy of the material, witch is known to have a strong influence on the yield stress surfaces (Arbab Chirani and Patoor 2000; Aleong et al. 2002; Lexcellent et al. 2002). So, a generalization of the equivalent stress and the equivalent transformation strain for anisotropic SMA is required. This is the main objective of the following parts of the paper. 


\subsection{Macroscopic approach}

\subsubsection{Equivalent stress for anisotropic SMA}

The isotropic equivalent stress has been generalized to take into account the anisotropy of the material. A dilated stress tensor, denoted by $\underline{\widetilde{\sigma}}$, is defined as a linear transformation of $\underline{\sigma}$ by:

$$
\underline{\sigma}=\underline{\underline{D}} \cdot \underline{\sigma}
$$

where $\underline{\underline{D}}$ contains constant material parameters. This affine transformation $\underline{\underline{D}}$ is chosen such as the Hill's hyper ellipsoid which becomes a hyper sphere in the dilated stress space. The form of $\underline{\underline{D}}$ is as following:

$$
\underline{\underline{D}}=\frac{1}{v}\left[\begin{array}{cccccc}
\frac{2 A}{3} \cos ^{2}(\varphi)+\frac{2 B}{3} \sin ^{2}(\varphi)+\frac{1}{3} & -\frac{A}{3} \cos ^{2}(\varphi)-\frac{B}{3} \sin ^{2}(\varphi)+\frac{1}{3} & -\frac{A}{3} \cos ^{2}(\varphi)-\frac{B}{3} \sin ^{2}(\varphi)+\frac{1}{3} & 0 & 0 & 0 \\
s y m & \left(\frac{A}{6}+\frac{B}{2}\right) \cos ^{2}(\varphi)+\left(\frac{A}{2}+\frac{B}{6}\right) \sin ^{2}(\varphi)+\frac{1}{3}\left(\frac{A}{6}-\frac{B}{2}\right) \cos ^{2}(\varphi)+\left(\frac{B}{6}-\frac{A}{2}\right) \sin ^{2}(\varphi)+\frac{1}{3} & 0 & 0 & 0 \\
\operatorname{sym} & \operatorname{sym} & \left(\frac{A}{6}+\frac{B}{2}\right) \cdot \cos ^{2}(\varphi)+\left(\frac{A}{2}+\frac{B}{6}\right) \sin ^{2}(\varphi)+\frac{1}{3} & 0 & 0 & 0 \\
0 & 0 & 0 & \sqrt{L} & 0 & 0 \\
0 & 0 & 0 & 0 & \sqrt{M} & 0 \\
0 & 0 & 0 & 0 & 0 & \sqrt{N}
\end{array}\right]
$$

with:

$$
\begin{aligned}
& A^{2}=\alpha \cos ^{2}(\varphi)+\beta \sin ^{2}(\varphi)+\gamma \cos (\varphi) \sin (\varphi) \\
& B^{2}=\alpha \sin ^{2}(\varphi)+\beta \cos ^{2}(\varphi)-\gamma \cos (\varphi) \sin (\varphi) \\
& \varphi=\frac{1}{2} \arctan \left(\frac{\delta}{\beta-\alpha}\right) \\
& v=\sqrt{\frac{1}{2}\left[\left(D_{11}-D_{12}\right)^{2}+\left(D_{11}-D_{13}\right)^{2}+\left(D_{12}-D_{13}\right)^{2}\right]}
\end{aligned}
$$

and:

$$
\begin{aligned}
& \alpha=\frac{3}{2}(F+H) \\
& \beta=\frac{1}{2} F+\frac{1}{2} H+2 G \\
& \delta=\sqrt{3}(H-F)
\end{aligned}
$$

where F, G, H, L, M, N are the Hill's criterion coefficients:

$$
F\left(\sigma_{11}-\sigma_{22}\right)^{2}+G\left(\sigma_{22}-\sigma_{33}\right)^{2}+H\left(\sigma_{33}-\sigma_{11}\right)^{2}+2 L \sigma_{12}^{2}+2 M \sigma_{23}^{2}+2 N \sigma_{13}^{2}=1
$$

The angle denoted $\varphi$, Eq. (3.10), corresponds to the inclination of the Hill's hyper ellipsoid in the stress space. In our case, thanks to transverse isotropy of the material $\varphi$ is equal to 0 . 
Based on this linear transformation, the equivalent stress for anisotropic material, $\sigma_{e q \text { ani }}$, is simply defined by substituting $\underline{\widetilde{\sigma}}$ for $\underline{\sigma}$ in Eq. (2.11):

$$
\sigma_{e q a n i}=\sigma_{e q a n i}\left(\overline{\dot{\sigma}}, y_{\sigma}\right)=\overline{\dot{\sigma}} \cdot g\left(y_{\sigma}\right)
$$

where $\overline{\widetilde{\sigma}}$ and $y_{\widetilde{\sigma}}$ are the $2^{\text {nd }}$ and $3^{\text {rd }}$ invariants of the dilated stress tensor $\underline{\widetilde{\sigma}}$ and $\mathrm{g}$ is the same function as the one introduced in the macroscopic criterion for isotropic material, Eq. (2.12). By the same way, the anisotropic "yield" surface is simply defined by substituting $\sigma_{e q \text { ani }}$ for $\sigma_{e q}$ in Eq. (2.14). Thanks to of the linearity of the tensor transformation, $\underline{\underline{D}}$, the anisotropic “yield" surface is convex (Betten, 1988).

\subsubsection{Material parameters identification procedure}

Seven material parameters have been introduced in the definition of the anisotropic "yield" surface: F, G, H, L, M, N (i.e., the Hill's criterion coefficients) and $a$ (i.e., the asymmetry parameter).

The parameter $a$ has been determined as in the isotropic case, Eq. (2.13). As the asymmetry could be different along the three axes, the average value has been taken into account. If $a_{i}$ denotes the asymmetry parameter along the axis $i$, it is the solution of:

$$
a_{i}=\frac{1}{2}\left[1-\cos \left\{3 \cos ^{-1}\left(\frac{\sigma_{i i t}^{0}}{\sigma_{i i c}^{0}}\right)\right\}\right]
$$

where $\sigma_{i i t}^{0}$ is the "yield" stress under pure tension and $\sigma_{i i c}^{0}$ the "yield" stress under pure compression for the axis $i$. Then, the material parameter $a$ is defined by an average value:

$$
a=\frac{a_{1}+a_{2}+a_{3}}{3}
$$

The six material parameters, F, G, H, L, M and N, can be determined from the "yield" stresses under pure tension and under pure shear as following:

$$
\left\{\begin{array} { l } 
{ F + H = \frac { 1 } { \sigma _ { 1 1 t } ^ { 0 } } } \\
{ F + G = \frac { 1 } { \sigma _ { 2 2 t } ^ { 0 } } } \\
{ G + H = \frac { 1 } { \sigma _ { 3 3 t } ^ { 0 } } }
\end{array} \quad \left\{\begin{array}{l}
L=\frac{1}{2 \cdot \sigma_{12 s}^{0}} \\
M=\frac{1}{2 \cdot \sigma_{13 s}^{0}} \\
N=\frac{1}{2 \cdot \sigma_{23 s}^{0}}
\end{array}\right.\right.
$$




\subsubsection{Comparison between the anisotropic "yield" surface and polycrystalline simulations}

As in the isotropic case, the polycrystalline model has been used to validate the anisotropic equivalent stress. To obtain the drawn texture, an elasto-plastic model describing the behavior of polycrystalline metals, based on the self-consistent scale transition method (Lipinski et al. 1990) has been used. A drawn loading has been applied to an initial isotropic texture of FCC metals until $50 \%$ of equivalent von Misès strain. Otherwise, the principle of the micro-macro model remains identical. 12 proportional loading paths have been considered in each plane $\left(\sigma_{11}, \sigma_{22}\right),\left(\sigma_{22}, \sigma_{33}\right),\left(\sigma_{11}, \sigma_{12}\right)$ and $\left(\sigma_{33}, \sigma_{23}\right)$. Figures 17 a-d show the "yield" surfaces obtained, on the one hand, with the polycrystalline model and, on the other hand, with the macroscopic approach. Table 1 gives the material parameters values used for the macroscopic "yield" surface. The agreement between these two sets of data is good.

\subsubsection{Comparison between the anisotropic "yield" surface and experimental results}

The identification procedure is similar to the one used in the previous section with the micromacro simulations. Nevertheless, with the performed experimental database, some parameters remain undetermined. Table 2 gives the coefficients for the anisotropic equivalent stress identified with the experimental database.

Figures 18, 19 and 20 show the comparison between the experimental results and the anisotropic "yield" surface in the three $\left(\sigma_{11}, \sigma_{22}\right),\left(\sigma_{22}, \sigma_{33}\right)$ and $\left(\sigma_{11}, \sigma_{12}\right)$ planes. The agreement between these two sets of data is good and shows that the anisotropic "yield" surface is flexible enough to describe the whole set of experimental data.

\subsubsection{Equivalent transformation strain for anisotropic SMA}

Insofar as the definition of equivalent stress has been changed, the definition of equivalent transformation strain has to be also modified.

The main idea here is that there is no reason for an anisotropic alloy to keep the same transformation power for all loading directions (Hu, 2004), that means:

$$
\begin{gathered}
\underline{\sigma}: \underline{\dot{\varepsilon}}^{t r} \neq c t e \\
\sigma_{\text {eq ani }} \dot{\varepsilon}_{\text {eq ani }}^{t r} \neq \underline{\sigma}: \underline{\underline{\hat{\varepsilon}}}^{t r}
\end{gathered}
$$

In this proposition the equivalent quantities (stress and strain) are supposed to be independent of the loading direction. Consequently, the assumption of power equality is not automatically validated (Eq. (3.18)). 
To validate this assumption, the transformation energy $W_{t r}$, at constant martensite volume fraction $z$, for every loading direction of the micro-macro simulations has been calculated using Eq. (3.19).

$$
W_{t r}=\int_{z} \underline{\sigma}: \underline{\dot{\varepsilon}}^{t r} d z
$$

The results are shown on figures $21 \mathrm{a}-\mathrm{d}$. The distance of a point to the origin is proportional to the transformation energy.

These curves show that the transformation energy, for a given value of martensite volume fraction, $z$, depends on the loading direction. A difference of $20 \%$ may be reached. Therefore the notion of "iso-transformation energy surfaces" is introduced.

These "surfaces" of iso-transformation energy can be represented by hyper ellipsoids without inclinations in the stress space and without asymmetry. It can also be noticed that their shape remains the same whatever the $z$ value. Consequently, their equation has the following form:

$$
f k_{11}^{2}+g k_{22}^{2}+h k_{33}^{2}+l k_{12}^{2}+m k_{13}^{2}+n k_{23}^{2}=1
$$

Where $f, g, h, l, m, n$ are constants and $\underline{k}$ is defined by:

$$
\underline{k}=W_{t r} \cdot \frac{\underline{\sigma}}{\|\underline{\sigma}\|}=W_{t r} \cdot \underline{N}
$$

$\underline{N}$ is the loading direction and $W_{t r}$ depends on $\underline{N}$ and $z$.

$$
W_{t r}(\underline{N}, z)=W_{t r}^{\text {tension }}(z) \cdot \alpha(\underline{N})
$$

As the equivalent transformation energy is the same whatever $\underline{N}$ and equal to the transformation energy $W_{t r}^{\text {tension }}$ for tension loading, it can be deduced:

$$
\int_{z} \sigma_{\text {eq ani }} \cdot \underline{\hat{E}}_{\text {eq ani }}^{t r} d z=W_{t r}^{\text {tension }}(z)=\frac{1}{\alpha(\underline{N})} W_{t r}(\underline{N}, z)=\frac{1}{\alpha(\underline{N})} \int_{z} \underline{\sigma}: \underline{\hat{s}}^{t r} \cdot d z
$$

So, for every proportional loading path:

$$
\varepsilon_{e q a n i}^{t r}=\frac{1}{\alpha(\underline{N})} \int_{z} \frac{\underline{\sigma}: \underline{\varepsilon}^{t r}}{\sigma_{e q a n i}} \cdot d z
$$

The equation of the energy surfaces, Eq. (3.20), may also be written as following:

$$
W_{t r}^{2}(\underline{N}, z)\left(f N_{11}^{2}+g N_{22}^{2}+h N_{33}^{2}+l N_{12}^{2}+m N_{13}^{2}+n N_{23}^{2}\right)=1
$$

As a consequence, $\alpha(\underline{N})$ is so calculated:

$$
\alpha(\underline{N})=\frac{W_{t r}(\underline{N}, z)}{W_{t r}^{\text {tension }}(z)}=\frac{\sqrt{f}}{\sqrt{f N_{11}^{2}+g N_{22}^{2}+h N_{33}^{2}+l N_{12}^{2}+m N_{13}^{2}+n N_{23}^{2}}}
$$

The identified values for $f, g, h, l, m, n$, considering $W_{t r}^{i j}(z)=W_{t r}\left(\underline{N}_{i j}=e_{i} \otimes e_{j}, z\right)$, are: 


$$
\begin{aligned}
& f=1 \\
& g=\left(\frac{W_{t r}^{\text {tension }}(z)}{W_{t r}^{22}(z)}\right)^{2} \\
& h=\left(\frac{W_{t r}^{\text {tension }}(z)}{W_{t r}^{33}(z)}\right)^{2} \\
& l=\left(\frac{W_{t r}^{\text {tension }}(z)}{W_{t r}^{12}(z)}\right)^{2} \\
& m=\left(\frac{W_{t r}^{\text {tension }}(z)}{W_{t r}^{13}(z)}\right)^{2} \\
& n=\left(\frac{W_{t r}^{\text {tension }}(z)}{W_{t r}^{23}(z)}\right)^{2}
\end{aligned}
$$

3.4.6. Relation between martensite volume fraction and anisotropic equivalent transformation strain (micro-macro simulations)

The micro-macro simulations on the polycrystalline-textured aggregate are used to compare the anisotropic equivalent transformation strain versus the volume fraction of martensite. Twelve loading paths are computed in the studied loading planes: $\left(\sigma_{11}, \sigma_{22}\right),\left(\sigma_{22}, \sigma_{33}\right)$, $\left(\sigma_{11}, \sigma_{12}\right)$ and $\left(\sigma_{33}, \sigma_{23}\right)$. The results are presented on the following $\left(\varepsilon_{e q \text { ani }}^{t r}, z\right)$ curves for the 48 loading paths considered (figures 22a-d).

The $\left(\varepsilon_{e q a n i}^{t r}, z\right)$ curves are quasi identical. A particularly good agreement is obtained for the isotropic plane of the material $(22,33)$. In the other planes, the observed slopes differences are vanishing small. Therefore, it can be concluded that there is a linear relation between the equivalent transformation strain $\mathcal{E}_{e q \text { ani }}^{t r}$ and the volume fraction of martensite $z$ :

$$
\varepsilon_{e q \text { ani }}^{t r}=\gamma . z
$$

\subsubsection{Relation between martensite volume fraction and anisotropic equivalent transformation} strain (experimental results)

In this paragraph, the martensite volume fraction in $\mathrm{Cu}-\mathrm{Al}-\mathrm{Be}$ specimen determined by electrical resistance measurements is compared to the equivalent transformation strain $\varepsilon_{e q \text { ani }}^{t r}$. Figure 23 shows the response on $\left(\varepsilon_{e q \text { ani }}^{t r}, z\right)$ graph for the nine tension-compression-torsion loading paths performed. 
These experimental results under tension-compression-torsion loadings on the $\mathrm{Cu}-\mathrm{Al}-\mathrm{Be}$ specimen show also quasi-identical $\left(\varepsilon_{e q a n i}^{t r}, z\right)$ curves. The proportionality relation between $\varepsilon_{e q \text { ani }}^{t r}$ and $z$ is so experimentally verified.

\section{Conclusion}

1. Macroscopic equivalent stresses have been defined for both isotropic and anisotropic SMA. For isotropic SMA, the associated yield stress surfaces coincide with those obtained by micro-macro simulations (Patoor and Berveiller, 1997) performed on an isotropic 1000 grains aggregate. For anisotropic SMA, the associated "yield" surfaces are in good qualitative and quantitative agreement, on one hand, with micro-macro simulations performed on polycrystalline textured aggregate, and on the other hand, with detection tests on $\mathrm{Cu}-\mathrm{Al}-\mathrm{Be}$ samples. The anisotropic "yield" surface is flexible enough to describe the whole set of experimental data.

2. Associated with each equivalent stress, the equivalent transformation strain has been defined.

3. The martensite volume fraction is followed experimentally thanks to electrical resistance measurement of the sample during super-elastic tension-torsion tests.

4. Finally, the linearity between the martensite volume fraction and the equivalent transformation strain has been validated in both cases of isotropy and anisotropy. This validation has been realized for isotropic SMA thanks to micro-macro simulations on the 1000 grains isotropic aggregate. For anisotropic SMA, the validation has been performed using both micro-macro simulations on the textured aggregate and tensiontorsion super-elastic tests with electrical resistance measurement of the sample. Therefore, the assumption $\varepsilon_{e q}^{t r}=\gamma . z$ (for isotropic SMA) or $\varepsilon_{e q ~ a n i}^{t r}=\gamma \cdot z$ (for anisotropic SMA) is fully established.

\section{Acknowledgments}

The authors wish to thank Professor Etienne Patoor for the implementation of the polycrystalline model. 


\section{References:}

Aleong, D., Dumont, C., Arbab Chirani, S., Patoor, E., McDowell, D.L., 2002. Transformation surfaces of a textured pseudoelastic polycrystalline $\mathrm{Cu}-\mathrm{Zn}$-Al shape memory alloy. J. Intel. Mat. Syst. Struct. 13 (12), 783-793.

Arbab Chirani, S., Patoor, E., 2000. Influence of the crystallographic texture on transformation surfaces in shape memory alloys. In: Proc. The third Japan-France seminar on intelligent materials and structures, Tokai, Japan.

Atanackovic, T., Müller, I., 1995. A new form of the coherency energy in pseudoelasticity. Meccanica 30, 467-474.

Balandraud, X., Ernst, E., Soos, E., 2000. Relaxation and creep phenomena in shape memory alloys. Z. Angew. Math. Phys. 51 (2), 171-203.

Ball, J., James, R., 1987. Fine phase mixtures as minimizers of energy. Arch. Rational Mech. and Anal. 100, 13-52.

Ball, J., James, R., 1992. Proposed experimental tests of a theory of fine microstructure and the two-well problem. Philos. Trans. Roy. Soc. London Ser. A 338, 389-450.

Barlat, F., Lian, J., 1989. Plastic behavior and stretchability of sheet metals. Part I: A yield function for orthotropic sheets under plane stress conditions. Int. J. Plasticity, 5. 51-56.

Barlat, F., Lege, D.J., Brem J.C., 1991. A six component yield function for anisotropic materials. Int. J. Plast. 7, 693-712.

Berveiller, M., Fischer, F.D., 1997. Mechanics of solids with phase changes. Springer-Verlag, Wien.

Betten, J., 1988. Applications of tensor functions to the formulation of yield criteria for anisotropic materials. . Int. J. Plast. 4, 29-46.

Bigoni, D., Piccolroaz, A., 2004. Yield criteria for quasibrittle and frictional materials. . Int. J. Solids Structures 41, 2855-2878.

Boehler, J.P., Sawczuk, A., 1970. Equilibre limite des sols anisotropes, J. Mécanique, 9, 5-33.

Bouvet, C., Calloch, S., Lexcellent, C., 2002. Mechanical behavior of a Cu-Al-Be shape memory alloy under multi-axial proportional and non proportional loadings. J. Eng. Mat. Tech. 124, 112-124.

Bouvet, C., Calloch, S., Lexcellent, C., 2004. A phenomenological model for pseudoelasticity of shape memory alloys under multi-axial proportional and non-proportional loadings. Eur. J. Mech. A Solids 23, 37-61.

Bouvet, C., Calloch, S., Taillard, K., Lexcellent, C., 2004. Experimental determinations of initial surface of phase transformation of SMA. J. Phys. IV 115, 29-36.

Boyd, J., Lagoudas, D., 1994. A thermomechanical constitutive model for the shape memory effect due to transformation and reorientation. In: Varadan, V. (Ed.). Proc. Int. Soc. Opt. Eng. $2189,276-288$. 
Boyd, J., Lagoudas, D. 1996. A thermomechanical constitutive model for the shape memory materials. Part I. The monolithic shape memory alloys. Int. J. Plast. 12, 805-842.

Chrysochoos, A., Lobel, M., Maisonneuve, O., 1993. Une analyse expérimentale du comportement thermomécanique d'un alliage à mémoire de forme de type $\mathrm{Cu}-\mathrm{Zn}-\mathrm{Al}$. C. R. Acad. Sci., Sér. II 316, 1031-1036.

Chrysochoos, A., Lobel, M., Maisonneuve, O., 1995. Thermomechanical coupling of pseudoelastic behavior of CuZnAl and NiTi alloys. C. R. Acad. Sci., Sér. II 320, 217-223.

Entemeyer, D., 1996. Etude micromécanique du comportement thermomécanique des alliages à mémoire de forme. $\mathrm{PhD}$ thesis, Université de Metz, France.

Falk, F., 1980. Model free energy, mechanics and thermodynamics of shape memory alloys. Acta Metall. 28, 1773-1780.

Falk, F., 1983. Ginzburg-Landau theory of static domain walls in shape memory alloys. Z. Phys. B 2, 61-77.

Falk, F., 1987. Driven domain walls in shape memory alloys. J. Phys. C 20, 2501-2509.

Falk, F., 1989. Pseudoelastic stress-strain curves of polycrystalline shape memory alloys calculated from single crystal data. Int. J. Engrg. Sci. 27, 277-284.

Fischer, F., Tanaka, K., 1992. A micromechanical model for the kinetics of martensitic transformation. Int. J. Solids Structures 29, 1723-1728.

Fischer, F., Berveiller, M., Tanaka, K., Oberaigner, E., 1994. Continuum mechanical aspect of phase transformation in solids. Arch. Appl. Mech. 64, 54-85.

Fremond, M., 1987. Mécanique des milieux continus. Matériaux à mémoire de forme. C. R. Acad. Sci., Sér. II 304, 239-244.

Fremond, M., 1990. Shape memory alloys. A thermomechanical model. In: Hoffman, K., Sprekels, J. (Eds.), Free Boundary Problems: Theory and Applications, Vol. I, pp. 295-306.

Gall, K., Sehitoglu, H., Maier, H.J., 1997. Asymmetric stress-strain response in shape memory alloys. In: Plast 97, Juneau, pp. 153-154.

Gall, K, Sehitoglu, H., Maier, H., Jacobus, K., 1998. Stress-induced martensitic transformations in polycrystalline $\mathrm{CuAlZn}$ shape memory alloys under different stress state. Met. Mat. Trans., 765-773.

Gonzalez, C.H., 2002. Etude des comportements électro-thermomécaniques et de la stabilisation martensitique d'alliages monocristallins à mémoire de forme base cuivre. $\mathrm{PhD}$ thesis, INSA de Lyon, France.

Helm, D., Haupt, P., 2001. Thermomechanical behavior of shape memory alloys. In: Proc. Of SPIES's Smart Structures and Materials, pp. 302-313.

Helm, D., Haupt, P., 2003. Shape memory behaviour: Modelling within continuum thermomechanics. Int. J. Solids Structures 40, 827-849. 
Hill, R., 1979. Theoretical plasticity of textured aggregates. Proc. Camb. Phil. Soc., Math. Phys. Sci., 85, 91-179.

Hill, R., 1987. On the limits set by plastic yielding to the intensity of singularities of stress. J. Mech. Phys. Solids, 35, 23.

Hu, W., 2004. Equivalent hardening work theorem. Philosophical Magazine Letters 84, 7-14.

Huang, W.M. and Zhu, J.J., 2002. To predict the behavior of shape memory alloys under proportional load. Mech. Materials, 34, 547-561.

Juhasz, L., Schnack, E., Hesebeck, O., Andrä, H., 2002. Macroscopic Modeling of Shape Memory Alloys under Non-proportional Thermo-mechanical Loadings. J. Intel. Mat. Syst. Struct. 13 (12), 825-836.

Karafillis, A.P., Boyce, M.C., 1993. A general anisotropic yield criterion using bounds and a transformation weighting tensor. J. Mech. Phys. Solids, 41, 1859-1886.

Kotil, T., Sehitoglu, H., Maier, H.J. and Chumlyakov, Y.I., 2002. Transformation and detwinning induced electrical resistance variations in NiTiCu. Materials and Engineering, A359, 280-289.

Lagoudas, D.C., Entchev, P.B., Popov, P., Patoor, E., Brinson, L.C., Gao, X., 2006. Shape memory alloys, Part II: Modeling of polycrystals. Mech. Mat., 38 430-462.

Lexcellent, C., Goo, B., Sun, Q., Bernardini, 1996. Characterization, thermomechanical behavior and micromechanical-based constitutive model of shape memory $\mathrm{Cu}-\mathrm{Zn}-\mathrm{Al}$ single crystals. Acta Mat. 44, 3773-3780.

Lexcellent, C., Vivet, A., Bouvet, C., Calloch, S., Blanc, P., 2002. Experimental and numerical determinations of the initial surface of phase transformation under biaxial loading in some polycrystalline shape-memory alloys. J. Mech. Phys. Solids 50, 2717-2735.

Lexcellent, C. and Blanc, P., 2004. Phase transformation yield surface determination for some shape memory alloys. Acta Materialia, 52, 2317-2324.

Lexcellent, C., Boubakar, M.L., Bouvet, C., Calloch, S., 2006. About modeling the shape memory alloy behaviour based on the phase transformation surface identification under proportional loadings and anisothermal conditions. Int. J. Solids Structures 43, 613-626.

Lim, T.J., McDowell, D.L., 1999. Mechanical behavior of an NiTi shape memory alloy under axial-torsional proportional and non proportional loading. J. Eng. Mat. Tech. 121, 9-18.

Lipinski, P., 1992. Modélisation du comportement des métaux en transformation élastoplastiques finies à partir de transition d'échelle. Thèse d'habilitation, Université de Metz, France.

Liu, Y., Xie, Z., Humbeck, J.V., Delaey, L., 1998. Asymmetry of stress-strain curves under tension and compression for NiTi shape memory alloys. Acta. Mat. 46 (12), 4325-4338.

Marketz, F., Fischer, F.D., 1996. Modelling the mechanical behavior of shape memory alloys under variant coalescence. Comp. Mat. Sci. 5, 210-226. 
Milton, G.W., 2002. The theory of composites. Cambridge monographs on applied and computational mathematics.

Niclaeys, C., Ben Zineb, T., Arbab Chirani, S., Patoor E, 2002. Determination of the interaction energy in the martensitic state. Int. J. Plast. 18, 1619-1647.

Patoor, E., Eberhardt, A., Berveiller, M., 1988. Thermomechanical behaviour of shape memory alloys. Arch. Mech. 40, 755-794.

Patoor, E., Eberhardt, A., Berveiller, M., 1994. Micromechanical modelling of the shape memory behavior. In: Brinson, L.C., Moran, B. (Eds.), Mechanics of phase transformation and shape memory alloys, AMD-Vol. 189, PVP-Vol. 292. ASME, pp. 23-37.

Patoor, E., El Amrani, M., Eberhardt, A., Berveiller, M., 1995. Determination of the origin for the dissymmetry observed between tensile and compression tests on shape memory alloys. J. Phys. IV 2, 495-500.

Patoor, E., Berveiller, M., 1997. Micromechanical modeling of thermoelastic behavior of shape memory alloys. In: Fischer, F.D., Berveiller, M. (Eds), CISM lecture notes $\mathrm{n}^{\circ} 368$ Mechanics of Solids with phase change, pp. 121-188.

Patoor, E., Lagoudas, D.C., Entchev, P.B., Brinson, L.C., Gao, X., 2006. Shape memory alloys, Part I: General properties and modeling of single crystals. Mech. Mat., 38 391-429.

Raniecki, B., Lexcellent, C., Tanaka, K., 1992. Thermodynamic model of pseudoelastic behaviour of shape memory alloys. Arch. Mech. 44 (3), 261-288.

Raniecki, B., Lexcellent,C., 1994. RL-models of pseudoelasticity and their specifications for shape memory alloys. Eur. J. Mech. A Solids 13, 21-51.

Raniecki, B., Lexcellent,C., 1998. Thermodynamics of isotropic pseudoelasticity in shape memory alloys. Eur. J. Mech. A Solids 17, 185-205.

Raniecki, B., Tanaka, K., Ziolkowski, A., 2001. Testing and modeling of NiTi SMA at complex stress state, Selected results of Polish-Japanese Cooperation. Mat. Sci. Res. Int. 2, 327-334.

Rogueda, C., Lexcellent, C., Bocher, L., 1996. Experimental study of pseudoelastic behavior of e $\mathrm{Cu}-\mathrm{Zn}$-Al polycrystalline SMA under tension-torsion proportional and non proportional loading tests. Arch. Mech. 48, 1025-1045.

Siredey, N., Patoor, E., Berveiller, M., Eberhardt, A., 1999. Constitutive equations for polycrystalline thermoelastic shape memory alloys. Part I. Intragranulaire interactions and behavior of the grain. Int. J. Solids Structures 36, 4289-4315.

Sittner, P., Hara, Y., Tokuda, M., 1995. Experimental study on the thermoelastic martensitic transformation in SMA polycrystal induced by combined external forces. Met. Mat. Trans. 26A, 2923-2935.

Sobotka, Z., 1969. Theorie des plastischen Fliessens von anisotropen Körpern. Zeit. Angew. Math. Mech., 49, 25-32. 
Tan, S., Xu, H., 1990. Observations on a CuAlNi single crystal, Cont. Mech. Ther. 2, 241-244.

Tanaka, K., 1986. A thermomechanical sketch of shape memory effect: one-dimensional tensile behavior. Res. Mech. 18, 251-263.

Tokuda, M., Ye, M., Takakura, M., Sitter, P., 1999. Thermomechanical behavior of shape memory alloy under complex loading conditions. Int. J. Plast. 15, 223-239.

Vacher, P., Lexcellent, C., 1991. Study of pseudoelastic behavior of polycrystalline shape memory alloys by resistivity measurements and acoustic emission. Proc. ICM VI 6, 231-236.

Vivet, A., Lexcellent, C., 1999. Observations and analysis of martensitic phase transformation on CuZnAl single crystals. J. Phys. VI 9, 411-418.

Wayman, C.M., 1983. Physical metallurgy; third revised and enlarged edition. Elsevier.

White, G. N. and Drucker, D. C., 1950. Effective Stress and Effective Strain in Relation to Stress Theories of Plasticity. J. appl. Phys., 21, 1013-1021 


\section{Figure captions:}

Fig. 1. The 12 loading paths in the $\left(\sigma_{11}, \sigma_{22}\right)$ plane.

Fig. 2 . The 12 loading paths in the $\left(\sigma_{11}, \sigma_{12}\right)$ plane.

Fig. 3. Shape of the "yield" surface in the $\left(\sigma_{11}, \sigma_{22}\right)$ plane.

Fig. 4. Shape of the "yield" surface in the $\left(\sigma_{11}, \sigma_{12}\right)$ plane.

Fig. 5. Equivalent stress versus equivalent transformation strain for the 24 loading paths considered.

Fig. 6. Martensite volume fraction versus equivalent transformation strain for the 24 loading paths considered.

Fig. 7. Transformation temperatures determination by electric resistance variation measurements.

Fig. 8. Geometry and sizes of the tubular specimen (in $\mathrm{mm}$ ).

Fig. 9. Comparison between experimental results and the isotropic "yield" surface in $\left(\sigma_{11}, \sigma_{22}\right)$ half-plane.

Fig. 10. Comparison between experimental results and the isotropic "yield" surface in $\left(\sigma_{11}, \sigma_{12}\right)$ quarter-plane.

Fig. 11. Comparison between experimental results and the isotropic "yield" surface in $\left(\sigma_{22}, \sigma_{33}\right)$ quarter-plane.

Fig. 12. Evolution of electrical voltage proportional to electrical resistance during a tensioncompression test.

Fig. 13. Evolution of voltage proportional to corrected electrical resistance during a tensioncompression test.

Fig. 14. Evolution of martensite volume fraction versus axial transformation strain during a loading-unloading tension test.

Fig. 15: Description of the nine tension-compression-torsion loading paths.

Fig. 16. Martensite volume fraction versus isotropic equivalent transformation strain for nine tension-compression-torsion loadings.

Fig. 17. Comparison between the "yield" surfaces obtained with the textured polycrystalline model and with the anisotropic approach in different planes.

Fig. 18. Comparison between experimental results and the anisotropic "yield" surface in $\left(\sigma_{11}, \sigma_{22}\right)$ half-plane. 
Fig. 19. Comparison between experimental results and the anisotropic "yield" surface in $\left(\sigma_{22}, \sigma_{33}\right)$ half-plane.

Fig. 20. Comparison between experimental results and the anisotropic "yield" surface in $\left(\sigma_{11}, \sigma_{12}\right)$ plane.

Fig. 21. "Iso-transformation energy surfaces": angle stands for the loading direction in the loading plane, and radius is proportional to the transformation energy for a given value of $z$.

Fig. 22. Martensite volume fraction versus the anisotropic equivalent transformation strain obtained with the textured polycrystalline model for the 48 loading paths considered.

Fig. 23. Martensite volume fraction versus the anisotropic equivalent transformation strain obtained on $\mathrm{Cu}-\mathrm{Al}-\mathrm{Be}$ for the nine tension-compression-torsion loading paths performed. 


\section{Table captions:}

Table 1: Coefficients for the anisotropic equivalent stress identified with textured polycrystalline simulations.

Table 2: Coefficients of the anisotropic equivalent stress for $\mathrm{Cu}-\mathrm{Al}-\mathrm{Be} \mathrm{SMA}$.

Table 3: Coefficients of the energy surface identified from the micro-macro model on the textured aggregate.

Table 4: Coefficients of the energy surface identified for $\mathrm{Cu}-\mathrm{Al}-\mathrm{Be}$ samples. 